\title{
ECOLOGICAL OBSERVATION OF AN ART GALLERY
}

\section{Priscilla Fenton}

Territory

A gallery space within the Student Union was selected as the area for an ecological observational study. This space exhibits high school art work from a state wide area. The building is located on the University campus and is the commons for the student and community activities. The gallery space is not distinct in that it is integrated into a lounge area in a well traveled section of the building (see Figure 1). The space is available to students, faculty, staff, visitors, conference participants and guests.

The gallery displayed a selection of 53 high school drawings at the time of these observations. It was observed for one hour in the late morning. This period previously had been noted as a time of increased traffic in the area.

Question

The study investigated the use of an integrated gallery space within a lounge area of a commons. Specifically, this observation was concerned with the nature of the penetration of the space by pedestrian traffic as well as by persons located in the lounge area (loungers). Did the gallery present barriers to be challenged or a configuration that invited the pedestrian or lounger to explore within the structure?

Observations

People were identified by the behavior they displayed towards the space. A few loungers were noted who initially located in the lounge area and then deliberately moved to view the drawings. Pedestrians were those who were traveling through the building. This group consisted of strollers, passers, speeders, and stoppers. Strollers casually viewed as they slowly walked, 


\section{Priscilla Fenton}

while passers made only visual contact with the space. Stoppers came to full distinct stops as they viewed the drawings. Strollers, passers, and stoppers penetrated the space, whereas the speeders ignored it. Several space economists penetrated the space by cutting through it as if to create the shortest distance between two points on their paths. Space economists rarely made sustained visual contact with the drawings.

Natural paths appeared to be located between points a. and c. as well as between b. and c. (see Figure 1). This space was penetrated most often by the space economists. Cutting through the space diagonally seemed to fulfill their need for swift passage. The spaces between the panels allowed this sort of penetration.

Point c., the area in front of the exterior sides of the north panels, was often penetrated. Loungers would pass these panels as they exited the lounge area. Space economists also entered the point c. area as they cut through the gallery. A few strollers and stoppers moved in a deliberate circular movement within the space as well as along its exterior. I suspect that these loungers were aware of my presence since they glanced at me several times during their stroll through the gallery space. They were reading before their gallery penetration and returned to this activity after the brief excursion. Perhaps this episode provided a break from their studies. Findings

These observations suggest that the gallery space is acknowledged as an element within the lounge area. Pedestrians, as well as loungers, penetrated the space, either deliberately or as an economic device, but the nature of the penetration by the pedestrians seemed to be more of the space economy variety. 


\section{Priscilla Fenton}

Perhaps placement of specific art work in this north west area of the gallery space would attract attention or create a "barrier" for the space economists. Points a. and b. seemed to be natural entry-exit areas. Rearrangement of the north panels may "capture" the space economists, however this strategy may be offensive to them. Perhaps these natural entry-exit areas are a function of the traffic flow off the main concourse, so changes in the installation of the art works may affect this feature more appropriately than arranging a different configuration of the panels. Strong pieces of work hung on the exterior of the panels off the main concourse may invite passers to enter the space and also slow down the speeders. The same treatment might be tried on the exterior of panels along the north side of the gallery space and point c. area. Effective art works in these locations may pull pedestrians from the east concourse as well as attract loungers to visit the gallery. The north spaces between the panels seemed to encourage entry into the inner gallery area. I recommend that the structure of the gallery space be retained since it seemed to encourage access through its perforated perimeters. If an increase in viewers is desired, installation devices that are visually appealing may be more successful in attracting the space economists, slowing down the speeders and enticing the loungers to get up and enter to view the exhibits. 


\section{Priscilla Fenton}

FIGURE 1

Observation Territory: Integrated Gallery Space

3

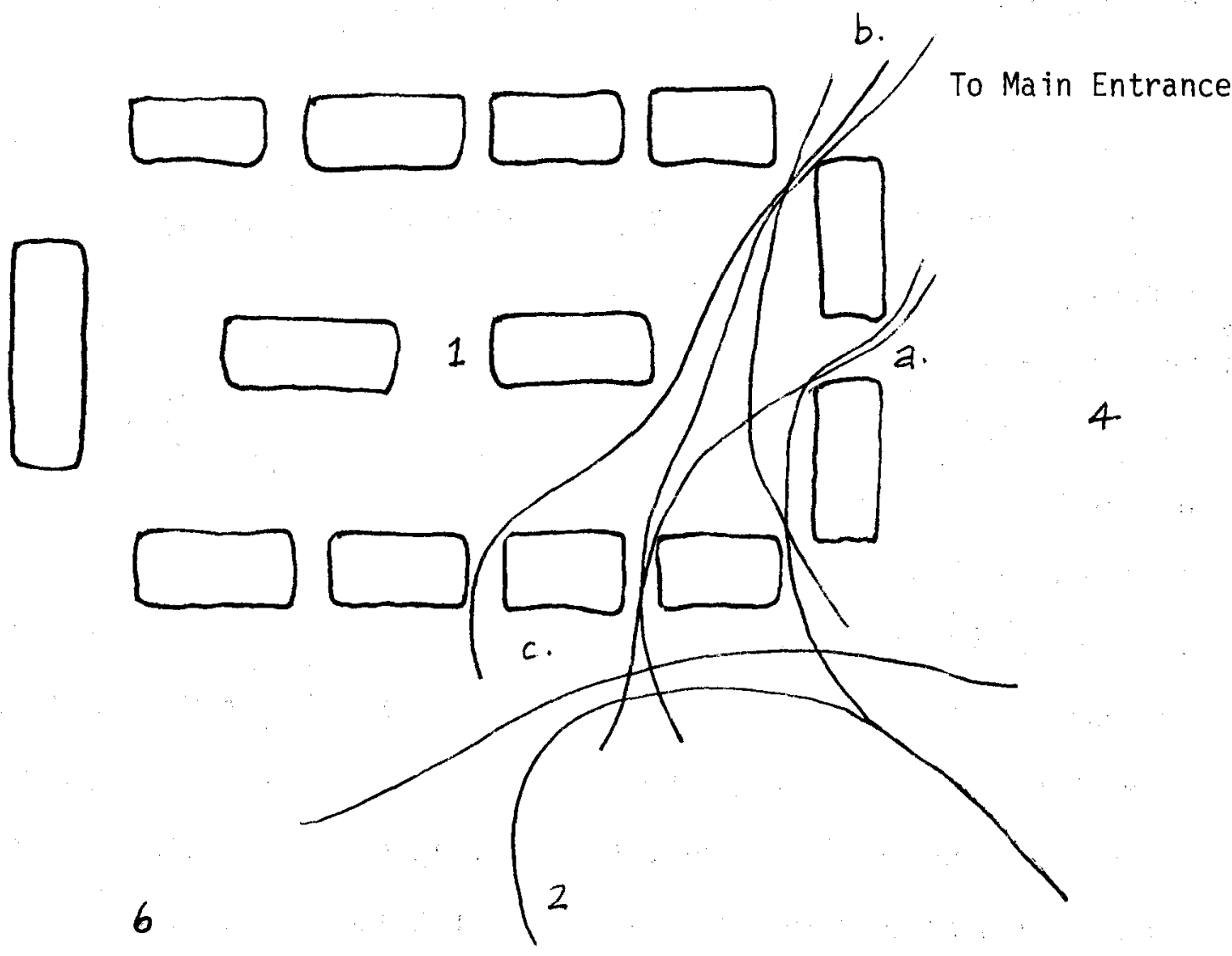

5

1. Gallery space

2. Lounge area (non-smoking)

3. Lounge area (smoking)

4. Ma in concourse

5. Observation post $A$

6. Observation post $B$

7. Concourse to east entrance a. Entrance-exit point

b. Entrance-exit point

c. Natural area 
FIGURE 2

Observation Territory: Phase One

(Raw Mapping)

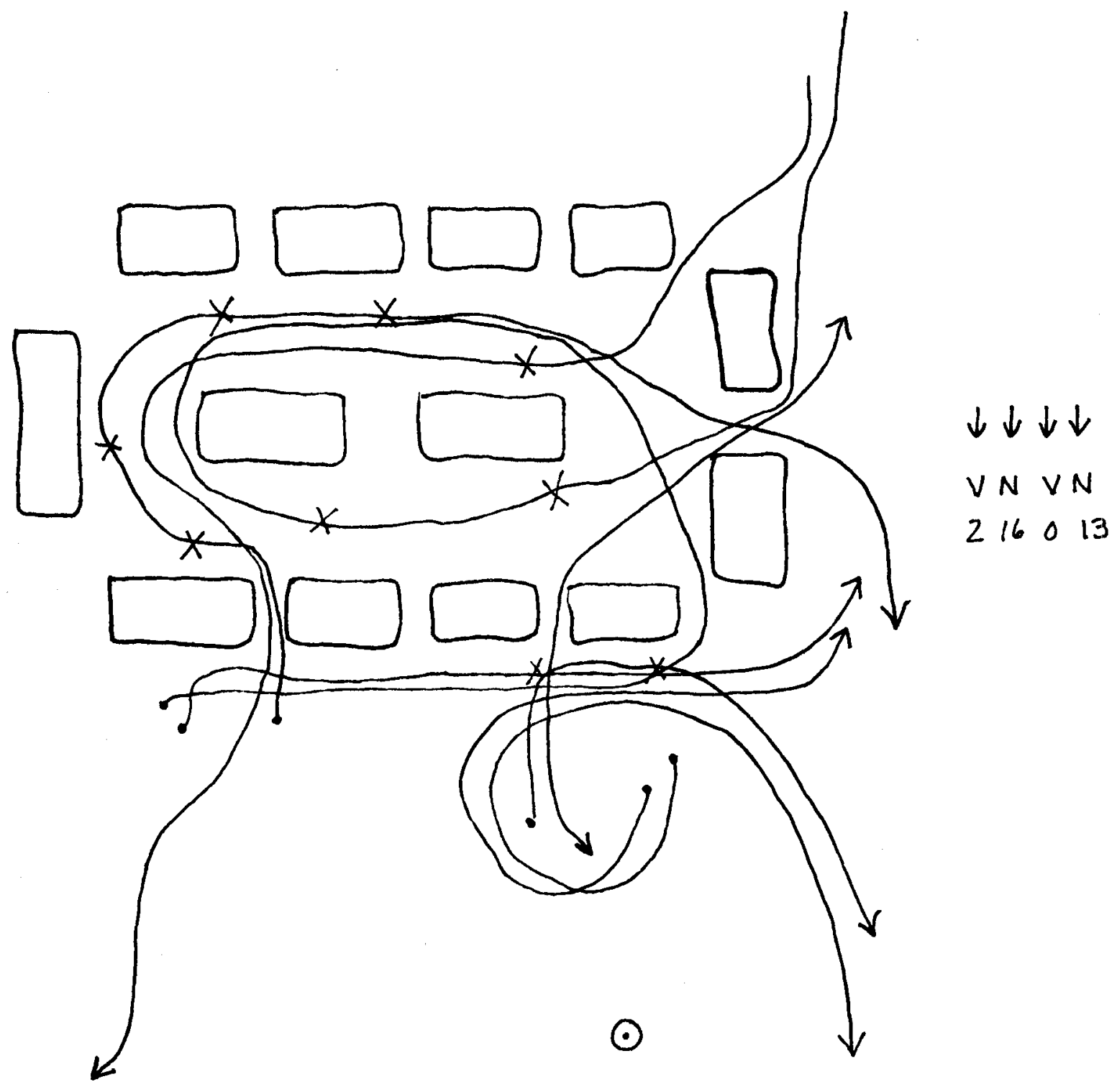

X Full stops

- Initial location

$\odot$ Observational post

N $\downarrow$ 


\section{Priscilla Fenton}

FIGURE 3

Observation Territory: Phase Two

(Raw Mapping)

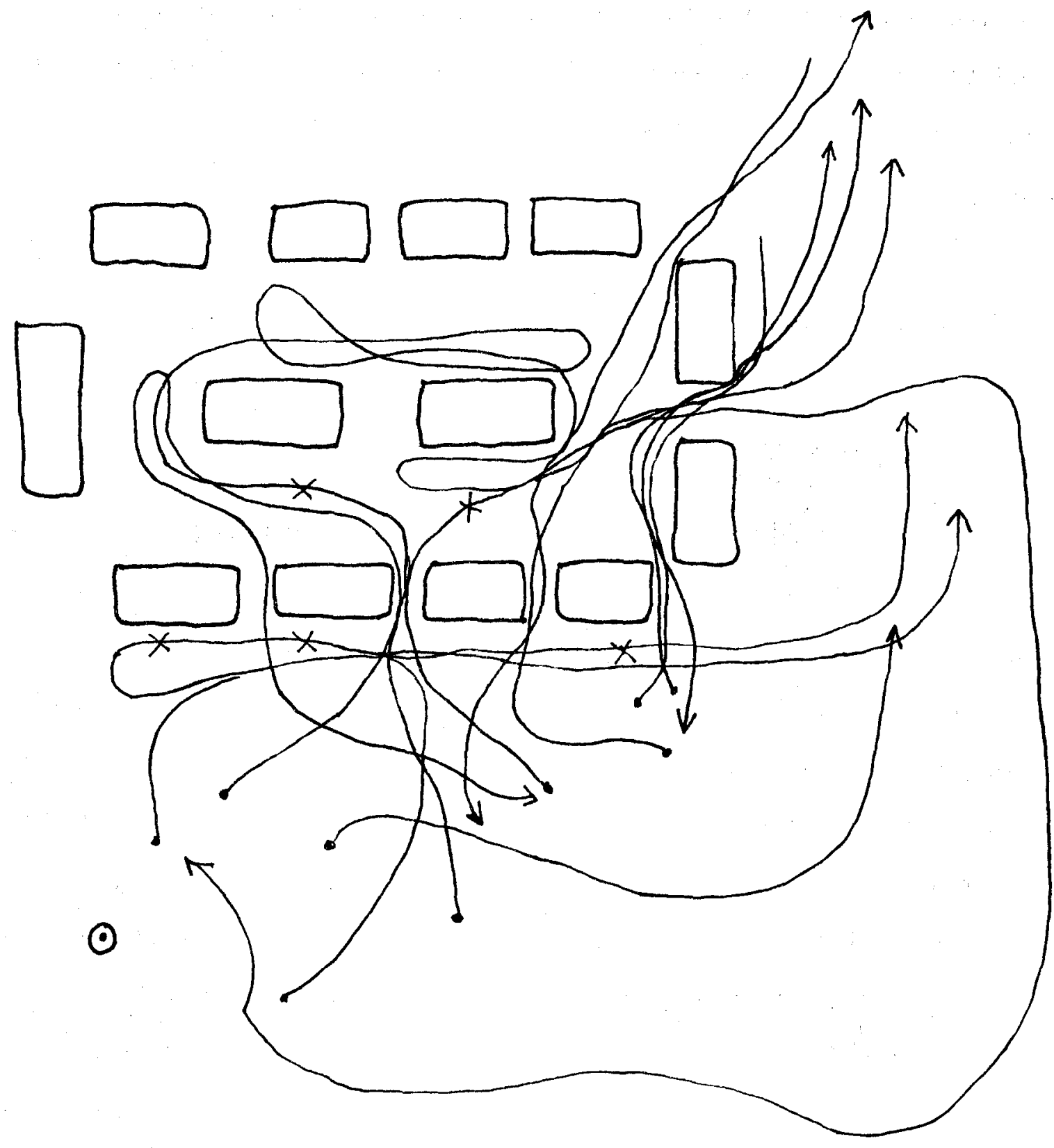

$\times$ Full stop

- Initial location

$40^{\circ}$ Observational Post 